\title{
A Study on Assessment of Health Related Quality of Life in COPD and Asthma Patients in a Tertiary Care Teaching Hospital
}

\author{
Ashok Kumar Malpani*, Manjunath Waggi, Medari Santhekudlur Mukunda, Kiran Jampa and \\ Mayakuntla Sindhuri
}

Department of Pharmacy Practice, NET Pharmacy College, NMCH and RC, Mantralayam Road, Raichur, Karnataka-584103, INDIA.

\begin{abstract}
Aim: The aim of this study was to evaluate the association between health-related quality of life (HROL) and disease severity using both disease specific and generic specific questionnaires and lung function measures. Methods: A survey was performed in patients with COPD and Asthma in tertiary care teaching hospital. One hundred and twenty (120) subjects (92 men and 28 women, mean age 48.6 years) completed the generic HRQL questionnaire; the Short Form 36 (SF-36) and disease-specific HRQL questionnaire; the St George's Respiratory

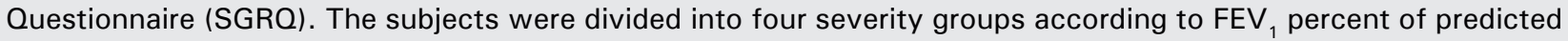
normal using two clinical guidelines: GOLD and BTS. Results: From our study it was observed that the mean scores of SF-36 PCS is 40.46, p $<0.0001$ and MCS is 40.22, p $<0.0001$ which showed an average HRQL and was significantly associated with COPD and Asthma. The COPD severity grades affected the SGRQ Total scores, varying from 67.8 to 22.9 (GOLD $p<0.0001$ ) and from 64.1 to 22.9 (BTS $p<0.0001$ ). The four stages of FVC\% predicted had an impact on HROL similar to the stages of FEV $\%$ predicted outlined from GOLD and BTS. Strong negative correlation $(-0.645, \mathrm{p}<0.0001)$ was observed between SF-36 and SGRQ total scores, strong negative correlation $(-0.847, \mathrm{p}<0.0001)$ between SGRO total scores and $\mathrm{FEV}, \% / \mathrm{FVC} \%$ predicted in contrast with positive correlation $(0.583, \mathrm{p}<0.0001)$ with SF-36 and $\mathrm{FEV}_{1} \% / \mathrm{FVC} \%$ predicted. Conclusion: The results showed that HROL in COPD deteriorates with disease severity and age. The results also showed that the level of HROL of COPD and Asthma subjects deteriorate considerably with increase in the severity of disease and such deterioration showed linear relation to the decrease in the $\mathrm{FEV}_{1} \%$ predicted normal values.
\end{abstract}

Key words: COPD, HRQL, SF-36, SGRO, PCS and MCS.

\section{INTRODUCTION}

Chronic Obstructive Pulmonary Disease (COPD) \& Asthma are the diseases which are under diagnosed and recognized as chronic diseases and has a very significant impact on individual's well being. COPD and Asthma are highly prevalent in India and many other developed countries.

COPD is a common respiratory condition involving the airways and characterized by airflow limitation, cough, sputum production and breathlessness associated with airflow obstruction. ${ }^{1,2}$ It affects more than $5 \%$ of the population and is associated with high morbidity and mortality rates. ${ }^{3}$ Whereas Asthma is a chronic disease characterized by recurrent attacks of breathless-
Submitted date :17-Jan-2015 Accepted date :25-Feb-2015

DOI: $10.5530 /$ ijopp.8.1.7

ness and wheezing, which vary in severity and frequency from person to person. ${ }^{4}$ In India, asthma affects majority of population with mortality rate of 7.5 age-standardized deaths per 100,000 as per WHO 2011. The prevalence of COPD varies considerably between countries and areas, from 3\% in India ${ }^{6}$ to $23 \%$ in the inner-city population of Manchester, UK. ${ }^{7}$ The US National Health and Nutrition Examination Survey (NHANES) III survey puts the prevalence of COPD in the US at $7 \% .^{8}$ The figure in Spain is similar, 9\%.

Over the past decade, more and more research on the development and validation of questionnaires has been undertaken
Address for

correspondence:

Prof. Dr Ashok Kumar Malpani,

Department of Pharmacy Practice,

NET Pharmacy College, NMCH\&RC, Mantralayam Road, Raichur,

Karnataka-584103

Phoneno:9845407765

E-mail:malpani_ashok@ rediffmail.com

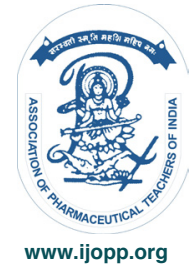




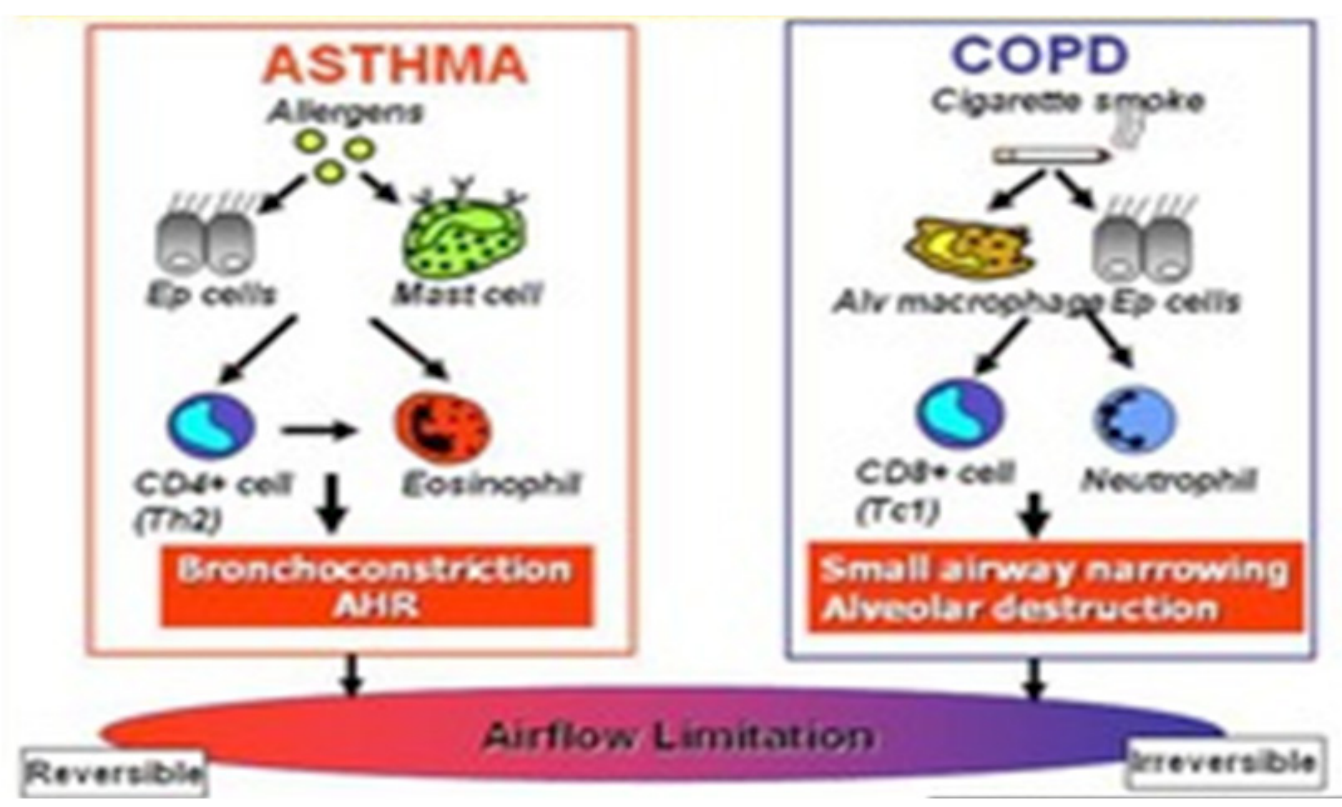

Graphical Abstract

to quantify the impact of disease on daily life and well-being from the COPD subject's point of view. ${ }^{10}$ Health-related quality of life (HRQL) and preferencebased HRQL instruments (utility instruments) are increasingly used in clinical studies. Although their use is established in many fields, such as oncology and gastrointestinal disease, questionnaires are rarely used as primary endpoints in randomised clinical studies of respiratory disease. One possible reason may be the lack of information about the patients' deterioration in HRQL when the disease progresses. The Medical Outcomes Study Short Form 36 (SF-36) and St George's Respiratory Questionnaire (SGRQ) are generic and disease-specific HRQL questionnaires, respectively. ${ }^{11,12}$ The SF-36 has been used in a number of therapeutic areas, including COPD, while the SGRQ has been widely used in both COPD and asthma research.

The present study was to evaluate the Physical Component Summary (PCS) and the Mental Component Summary (MCS) by using Short Form 36 (SF-36) and St George's Respiratory Questionnaire (SGRQ) which are generic and disease-specific HRQL questionnaires, respectively. This also may show association between HRQL and COPD stages using forced expiratory volume in one second as a percentage of predicted normal values ( $\mathrm{FEV}_{1} \%$ predicted) by means of two clinical guidelines for COPD, taking into account the influence on HRQL of age, gender, smoking status and socio-economic background. In addition association between HRQL and forced vital capacity as a percentage of predicted normal values (FVC \% predicted) was also evaluated.

\section{METHODS}

\section{Study sample}

A total of 136 subjects with acute exacerbations and those who were diagnosed with COPD and Asthma, selected from department of Pulmonary Medicine were invited; 128 subjects took part in this survey and data from 120 subjects were available.

\section{Procedure}

After initial instruction from the superintendent, a physician and a clinical pharmacist the questionnaires were completed unaided by subjects in the order of SF-36 and SGRQ. A few subjects did not complete all questionnaires due reason not known.

\section{Severity of COPD}

The subjects were divided into four severity groups according to $\mathrm{FEV}_{1} \%$ predicted (pre-bronchodilator) using two different guidelines: the updated version (not yet published) of the GOLD guidelines ${ }^{13}$ and the BTS guidelines. ${ }^{14}$ (Table 1 )

\section{HRQL questionnaires}

\section{Short Form 36}

The most widely used generic questionnaire, the Medical Outcomes Study Short Form 36 (SF-36), has been widely accepted in recent years as the best generic HRQL measurement. It contains 36 items divided into eight domains: Physical Functioning (PF), Role-Physical (RP), Bodily Pain (BP), General Health (GH), Vitality (VT), Social Functioning (SF), Role-Emotional (RE) and Mental Health (MH). These domains create a pro- 


\begin{tabular}{|c|c|c|}
\hline \multicolumn{3}{|c|}{ Global Initiative for Chronic Obstructive Lung Disease, GOLD [3]: FEV $/$ FVC $<70 \%$} \\
\hline Stage I & Mild COPD & $\mathrm{FEV}_{1} \geq 80 \%$ \\
\hline Stage II & Moderate COPD & $\mathrm{FEV}_{1} 50-79 \%$ \\
\hline Stage III & Severe COPD & $\mathrm{FEV}_{1} 30-49 \%$ \\
\hline Stage IV & Very Severe COPD & $\mathrm{FEV}_{1}<30 \%$ \\
\hline \multicolumn{3}{|c|}{ British Thoracic Society, BTS [2]: FEV $/$ FVC $<70 \%$ and FEV $_{1}<80 \%$ predicted } \\
\hline Stage 0 & Mild COPD & $\mathrm{FEV}_{1} \geq 80 \%$ \\
\hline Stage I & Moderate COPD & FEV $60-79 \%$ \\
\hline Stage II & Severe COPD & $\mathrm{FEV}_{1} 40-59 \%$ \\
\hline Stage III & Very Severe COPD & $\mathrm{FEV}_{1}<40 \%$ \\
\hline \multicolumn{3}{|c|}{$\begin{array}{l}\text { A group labeled BTS stage o was created for subjects with } \mathrm{FEV}_{1} \geq 80 \% \text { predicted: i.e. identical with mild COPD } \\
\text { according to the GOLD criteria. }\end{array}$} \\
\hline \multicolumn{3}{|c|}{ Table 2: Subject characteristics } \\
\hline & teristic & Mean data (range) \\
\hline & nber agreed & 120 \\
\hline & nen $n=120$ & $92 / 28$ \\
\hline Mea & $s$ (range) $n=120$ & $64.3(40-79)$ \\
\hline & tatus $n=120$ & Smoker, $n=74$ Non-smoker, $n=46$ \\
\hline Educ & lifications $n=120$ & $\begin{array}{l}\text { Primary education, } n=85 \text {, Secondary } \\
\text { education, } n=30 \text {, Higher education, } n=05\end{array}$ \\
\hline & nt disease & $\begin{array}{c}\mathrm{TB}=09, \mathrm{HTN}=10, \mathrm{DM}=02, \mathrm{GERD}=02 \& \\
\text { None }=97\end{array}$ \\
\hline & ry disease & COPD $=110 \&$ Asthma $=10$ \\
\hline
\end{tabular}

file of the subject. Two summary scores can also be aggregated, the Physical Component Summary (PCS) and the Mental Component Summary (MCS). Scores range from 0 to 100 , with higher scores representing better HRQL. ${ }^{11}$

\section{St George's Respiratory Questionnaire}

The best-known and most frequently used diseasespecific HRQL questionnaire for respiratory diseases is the St George's Respiratory Questionnaire (SGRQ). ${ }^{12,15}$ The SGRQ is a standardized, self-administered questionnaire for measuring impaired health and perceived HRQL in airways disease. It contains 50 items, divided into three domains: Symptoms, Activity and Impacts. A score is calculated for each domain and a total score, including all items, is also calculated. Each item has an empirically derived weight. Low scores indicate a better HRQL. Recent publications by the developer (PW Jones) have confirmed that the minimal important difference relevant to the patients (MID) is 4 on a scale of 0 to $100 .^{16,17}$

\section{Statistical analysis}

Statistical analysis was performed using an analysis of covariance model with HRQL scores as dependent variable. Three different approaches to analysis were performed using different classification of severity of
COPD from GOLD and BTS guidelines. This classification was used as factor in the analysis. In all cases age, gender, smoking status and socio-economic background was used as covariates. These variables showed sign of influence on the HRQL measures and for the sake of comparability a unified model was selected for the analysis. An additional classification of severity based on FVC $\%$ predicted normal was also investigated with the same model with classification into four groups: stage I: > 95\%, stage II: $95-81 \%$, stage 3: $80-66 \%$ and stage IV; $<66 \%$. These levels were chosen to have approximately equal number of patients in each group. Data presented in tables are adjusted least-square means from the adopted model.

\section{RESULTS}

\section{Subject characteristics}

The mean age of the 120 subjects ( $92 \mathrm{men} / 28$ women) was 64.3 years (range: $40-79$ years). Seventy four subjects were smokers and 46 were non-smokers. Eighty five subjects were with primary education, 30 with secondary education and 5 were with higher education. Among 120 subjects, 110 patients reported with COPD and 10 with Asthma. (Table 2) 


\begin{tabular}{cccccccccc}
\multicolumn{8}{c}{ Table 3: Average PCS and MCS for SF-36 } \\
\cline { 2 - 5 } & PF & RP & BP & GH & VT & SF & RE & MH & AVG \\
\hline PCS & 54.45 & 49.16 & 65.61 & 44.1 & 44.58 & 56.87 & 51.11 & 54.4 & 40.46 \\
MCS & 54.45 & 49.16 & 65.61 & 44.1 & 44.58 & 56.87 & 51.11 & 54.4 & 40.22 \\
\hline
\end{tabular}

Though the values are same for both PCS and MCS but average values are different

\section{Table 4: SGRQ scores of healthy subject/study subjects}

\begin{tabular}{lcccc} 
& Impact Score & Activity Score & Symptoms Score & Total Score \\
\hline Normal subjects & $1-3$ & $7-12$ & $9-15$ & $5-7$ \\
Study subjects & 29.11 & 35.03 & 46.47 & 33.05 \\
\hline
\end{tabular}

\section{$\mathrm{HRQL}$ in relation to SF-36}

Our study had a PCS score of $40.46 \pm 7$ for 120 patients; this indicates below average health status, COPD and Asthma being significantly affecting the physical activity of the patients. MCS had a score of $40.22 \pm 7.7$ denoting a significant decrease in the psychological wellbeing, social, role functioning of the subjects Mental component score for SF-36 was calculated for 120 patients included in our study, the details of the mean scores obtained were aggregated and average scores are summarized in (Table 3).

\section{HRQL in relation to SGRQ}

The ideal total score desirable for a healthy subject is 6 . In our study subjects the total score is 33.95 which are considered as an average quality of life when compared to normal subjects (Table 4).

\section{HRQL in relation to COPD severity according to GOLD}

The differences in SF-36 PCS between the four severity groups were statistically significant $(\mathrm{p}=0.0001)$. The scores for SF-36 (PCS) were 43.72 in the stage I group and 32 in the stage IV group. The corresponding scores for SF-36 MCS were 42.11 and 33 in stages I and IV respectively $(\mathrm{p}=0.0001)$ (Table 5$)$. There was also a statically significant difference in the SGRQ Total scores between the severity groups $(p=0.0001)$ except for Impact score $(p=0.01)$. It was observed that the severity grades affected indicates in the following (Figure 1) the level of SGRQ Total as follows: stage I: 22.90, stage II: 39.90, stage III: 59.44 and stage IV: 67.84 respectively.

\section{HRQL in relation to COPD severity according to BTS}

The scores for SF-36 (PCS) were 43.72 in the stage 0 and 33.36 in stage III $(\mathrm{p}=0.0001)$. The corresponding scores for SF-36 MCS were 42.11 and 35.10 in stages 0 and III, respectively $(\mathrm{p}=0.0001)$ (Table 6 ).

The severity grades of SGRQ Total scores as follows: stage 0: 22.90 , stage I: 37.24 , stage II: 53.19 , and stage III: 64.18. There was a statistically significant difference in the SGRQ Total scores between the severity groups $(p=0.0001)$. Except for the impact score. $(p=0.01)$.

\section{HRQL In relation to FVC\% Predicted}

The four stages of $\mathrm{FVC} \%$ pred. $(>95 \%, 95-81 \%$, $80-66 \%,<66 \%)$ had an impact on HRQL similar to the stages of FEV1 \% predicted outlined from GOLD and BTS. SGRQ total score varied from 21.6(>95\%) to $61(<66 \%)(\mathrm{p}=<0.0001)$. Whereas for SF-36 PCS and MCS scores varied from 45.1(>95\%) to $33.7(<66 \%)$ and $43.9(>95 \%)$ to $35.5(<66 \%)$ respectively (Table 7 ).

\section{Correlation between the instruments}

In brief it can be stated the (Table 8) shows Pearson correlation coefficients between the different instruments and $\mathrm{FEV}_{1} \%$ and $\mathrm{FVC} \%$ predicted. All the questionnaires were correlated with each other. The correlation coefficients between SGRQ and SF-36

\section{Table 5: Health-related quality of life scores based on -GOLD criteria}

\begin{tabular}{|c|c|c|c|c|c|}
\hline Scales & $\begin{array}{c}\geq 80 \% \\
\text { Stage I } n=68\end{array}$ & $\begin{array}{c}79-50 \% \\
\text { Stage II } n=32\end{array}$ & $\begin{array}{c}49-30 \% \\
\text { Stage III } n=14\end{array}$ & $<30 \%$ Stage IV $n=6$ & $\begin{array}{c}\text { p-value } \\
\text { (all stages) }\end{array}$ \\
\hline SF36 PCS & $43.72(6.01)$ & $37.26(5.95)$ & $35.5(5.70)$ & $32(3.84)$ & 6.59555E-35 \\
\hline SF36 MCS & $42.11(7.02)$ & $39.70(7.68)$ & $35.32(6.12)$ & $33(10.58)$ & $1.02 E-30$ \\
\hline SYMPTOM SCORE & $44.31(9.32)$ & $48.09(13)$ & $54.60(7.14)$ & $63.07(10.70)$ & 5.11146E-16 \\
\hline ACTIVITY SCORE & 23.33 (8.93) & $44.50(12.9)$ & $57.01(6.11)$ & $65.67(2.39)$ & 0.000102 \\
\hline IMPACT SCORE & $15.96(5.24)$ & $34.72(12.9)$ & $62.34(7.22)$ & $70.57(4.97)$ & 0.01045563 \\
\hline TOTAL SCORE & $22.90(3.96)$ & $39.90(9.71)$ & $59.44(4.87)$ & $67.84(1.82)$ & 1.57E-06 \\
\hline
\end{tabular}




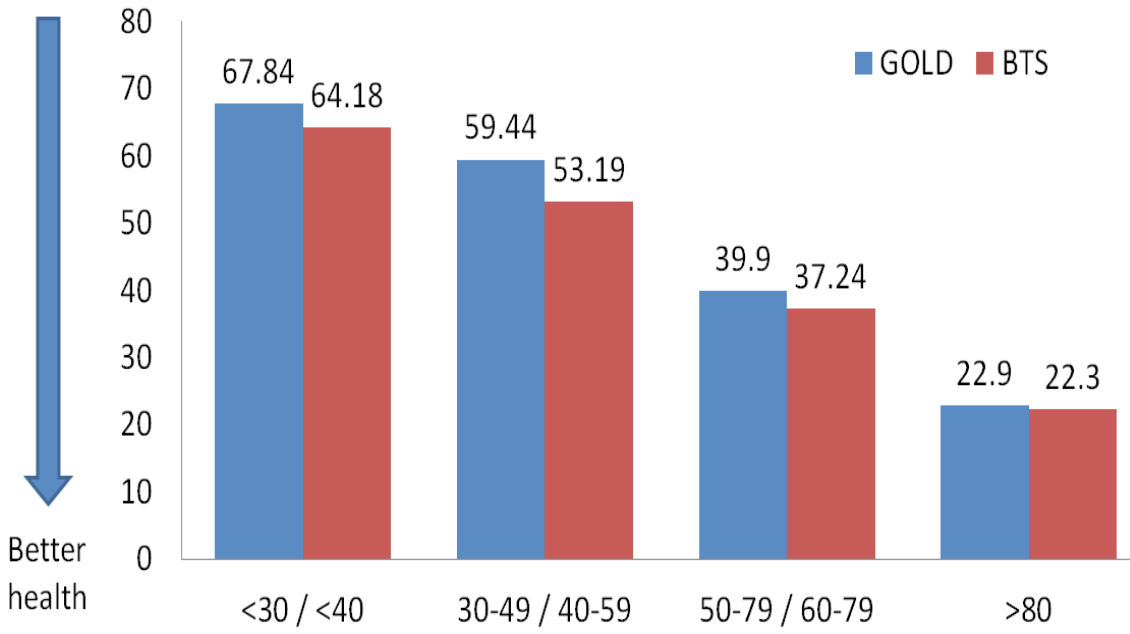

Figure 1: SGRQ TOTAL SCORES -GOLD AND BTS CRITERIA FEV $1 \%$ Predicted

Using the GOLD stages, the number of patients was distributed and the SGRO total scores were $22.90(>80 \%, n=68), 39.90(50-79 \%, n=32), 59.44(30-49 \%, n=14)$ and 67.84 $(<30 \mathrm{n}=6)(\mathrm{p}<0.0001)$ (Figure 1).

Using the BTS criteria, the number of patients was distributed and the SGRQ total scores were $22.90(>80 \%, n=68), 37.24(60-79 \%, n=26), 53.19(40-59 \%, n=11)$ and 64.18 $(<40 \mathrm{n}=15)(\mathrm{p}<0.0001)$ (Figure 1).

Table 6: Health-related quality of life scores according to BTS criteria

\begin{tabular}{|c|c|c|c|c|c|}
\hline Scales & $\begin{array}{c}\geq 80 \% \\
\text { Stage } 0 \mathrm{n}=68\end{array}$ & $\begin{array}{c}79-50 \% \\
\text { Stage I } n=26\end{array}$ & $\begin{array}{c}49-30 \% \\
\text { Stage II } n=11\end{array}$ & $\begin{array}{c}<30 \% \\
\text { Stage III } n=15\end{array}$ & $\begin{array}{c}\text { p-value } \\
\text { (all stages) }\end{array}$ \\
\hline SF36 PCS & $43.72(6.01)$ & $37.83(6.40)$ & $36.23(4.42)$ & $33.36(4.86)$ & 7E-35 \\
\hline SF36 MCS & $42.11(7.02)$ & $40.39(7.45)$ & $35.16(6.70)$ & $35.1(8.51)$ & $1 \mathrm{E}-30$ \\
\hline SYMPTOM SCORE & $44.31(9.32)$ & 47.39 (14) & $52.96(7.71)$ & $57.79(9.44)$ & $5 E-16$ \\
\hline ACTIVITY SCORE & $23.33(8.93)$ & $42.35(13.16)$ & $53.21(5.78)$ & $61.98(5.15)$ & 0.0001 \\
\hline IMPACT SCORE & $15.96(5.24)$ & $31.15(10.56)$ & $53.25(9.52)$ & 67.44 (5.79) & 0.0105 \\
\hline TOTAL SCORE & $22.90(3.96)$ & $37.24(8.32)$ & $53.19(5.67)$ & $64.18(4.26)$ & $2 \mathrm{E}-06$ \\
\hline
\end{tabular}

Table 7: HRQL in relation to FVC\% Predicted

\begin{tabular}{|c|c|c|c|c|c|}
\hline \multirow[b]{2}{*}{ SCALES } & \multicolumn{5}{|c|}{ FVC\% PREDICTED } \\
\hline & $\begin{array}{c}\geq 95 \% \\
\text { Stage } 0 n=23\end{array}$ & $\begin{array}{c}95-81 \% \\
\text { Stage I } n=59\end{array}$ & $\begin{array}{c}80-66 \% \\
\text { Stage II } n=16\end{array}$ & $\begin{array}{c}<66 \% \\
\text { Stage III } n=22\end{array}$ & $\begin{array}{c}\text { p-value } \\
\text { (all stages) }\end{array}$ \\
\hline SF36 PCS & $45.1(5.8)$ & $42.1(6.40)$ & $36.9(4.5)$ & $33.7(4.9)$ & 1.07E-58 \\
\hline SF36 MCS & $43.9(6.7)$ & $40.9(7.1)$ & $38.4(7.9)$ & $35.5(7.8)$ & $2.6 \mathrm{E}-58$ \\
\hline SYMPTOM SCORE & $39(12.14)$ & $47.5(8.4)$ & $48.4(11.1)$ & $55.32(22)$ & 3.5E-41 \\
\hline ACTIVITY SCORE & $19(8.93)$ & $28.3(8.9)$ & $49.1(11.3)$ & $59.38(6)$ & 3.3E-52 \\
\hline IMPACT SCORE & $17.56(8)$ & $17.95(7.6)$ & $39.1(10.8)$ & $63.7(7.8)$ & $6.6 \mathrm{E}-56$ \\
\hline TOTAL SCORE & $21.6(6.2)$ & $26(6.4)$ & $43.7(6.8)$ & $61(6.4)$ & $4.9 \mathrm{E}-56$ \\
\hline
\end{tabular}

PCS/MCS were -0.645 and -0.369 , respectively. The lowest correlation was been seen between SF-36 MCS and SF-36 PCS $(r=0)$. The correlations between SGRQ and either $\mathrm{FEV}_{1} \%$ predicted or $\mathrm{FVC} \%$ predicted were similar (-0.861 and -0.902, respectively).

\section{DISCUSSION}

The study aimed to explore the feasibility of a routine collection of HRQL information in an inpatient setting. A generic questionnaire SF-36 and a disease spe- cific SGRQ questionnaire were chosen to examine the HRQL assessment in patients with COPD and asthma. A total of 120 patients were included in our study from the pulmonary medicine department who are suffering from COPD and asthma. Out of them male patients were 92 and female patients were 28. Social behavior with regard to smoking habits showed that 74 (61.6\%) were smoker and $46(38.3 \%)$ were nonsmoker which implied smokers are more prone to COPD and asthma. Educational qualification for patients with primary edu- 
Table 8: Pearson's correlation $(r)$ for various parameters

\begin{tabular}{|c|c|c|c|c|c|c|c|c|}
\hline & $\begin{array}{c}\text { SF-36 } \\
\text { PCS }\end{array}$ & SF-36-MCS & $\begin{array}{l}\text { SYMPTOM } \\
\text { SCORE }\end{array}$ & $\begin{array}{l}\text { ACTIVITY } \\
\text { SCORE }\end{array}$ & $\begin{array}{l}\text { IMPACT } \\
\text { SCORE }\end{array}$ & $\begin{array}{l}\text { TOTAL } \\
\text { SCORE }\end{array}$ & $\begin{array}{c}\text { FVC } \\
\text { \%PRED }\end{array}$ & FEV $1 \%$ PRED \\
\hline SF-36 PCS & 1 & - & - & - & - & - & - & - \\
\hline SF-36-MCS & 0.0056 & 1 & - & - & - & - & - & - \\
\hline $\begin{array}{l}\text { SYMPTOM } \\
\text { SCORE }\end{array}$ & -0.141 & -0.292 & 1 & - & - & - & - & - \\
\hline ACTIVITY SCORE & -0.690 & -0.284 & 0.326 & 1 & - & - & - & - \\
\hline IMPACT SCORE & -0.603 & -0.363 & 0.284 & 0.833 & 1 & - & - & - \\
\hline TOTAL SCORE & -0.645 & -0.369 & 0.415 & 0.922 & 0.972 & 1 & - & - \\
\hline FVC \%PRED & 0.548 & 0.359 & -0.503 & -0.803 & -0.807 & -0.861 & 1 & - \\
\hline \multirow[t]{2}{*}{ FEV $_{1} \%$ PRED } & 0.583 & 0.380 & -0.493 & -0.847 & -0.902 & -0.902 & 0.966 & 1 \\
\hline & PF & RP & BP & GH & VT & SF & RE & MH \\
\hline FVC \%PRED & 0.456 & 0.476 & 0.626 & 0.601 & 0.560 & 0.480 & 0.151 & 0.512 \\
\hline FEV $\%$ \%PRED & 0.451 & 0.505 & 0.655 & 0.646 & 0.617 & 0.487 & 0.156 & 0.542 \\
\hline
\end{tabular}

cation is $85(70.8 \%)$, with secondary education $30(25 \%)$ and are with higher education 5 (4.1\%).

The concurrent disease status of patients showed that $23(19.2 \%)$ patients were reported with concurrent diseases. Among the respiratory diseases 110 (91.66\%) patients with COPD and $10(8.33 \%)$ patients with asthma (Table 2).

PCS values were between the two extremes 0 and 100, with zero indicating the lowest HRQL and 100 indicates the better HRQL. As the value increases from 0 to 100 it represents better health. In our study the total score of PCS is 40.46. Which means that patients have not achieved average health. Though this value is within the theoretical range it does not show a good correlation. Mental component of SF-36 questionnaire is calculated to assess the psychological distress and well being, social and role functioning, and overall vitality. (Table 3)

Hence, it is observed that there is a significant evidence for an increase or decrease in PCS with changes in the 8 domains of SF-36. Multiple Regression Analysis showed that one value of each domain in SF-36 (PF, RP, $\mathrm{BP}, \mathrm{GH}, \mathrm{VT}, \mathrm{SF}, \mathrm{RE}, \mathrm{MH})$ is associated with the 0.178 , $0.106,0.131,0.106,0.022,0.0008$ increase and 0.005 , 0.11 decrease the PCS value respectively.

It was also noticed that there is a significant evidence for an increase or decrease in MCS with changes in the 8 domains of SF-36. Multiple Regression Analysis showed that one value of each domain in SF-36 (PF, $\mathrm{RP}, \mathrm{BP}, \mathrm{GH}, \mathrm{VT}, \mathrm{SF}, \mathrm{RE}, \mathrm{MH})$ is associated with the decrease in $0.104,0.036,0.041$ and increase in 0.008 , $0.01,0.0008,0.121,0.131$ and 0.267 increase in the MCS value respectively.

Similarly disease specific questionnaire was also formulated for self-evaluation by the patients and will be referred as SGRQ hence forth. A low score of SGRQ indicates a better health. In our study a total SGRQ score of $33.95 \mathrm{SD} \pm 15.8$; which is five times greater than the normal (5-7) which denotes patients have a very low HRQL (Table 4).

SYMPTOMS SCORE: A score of $47.46 \mathrm{SD} \pm 11.2$; which is very high compared to a normal individuals (9-15). This indicates majority of patients are suffering with COPD/Asthma from past one year (Table 4).

ACTIVITY SCORE: A score of 35.03 SD \pm 17.3 ; is also high compared to normal individuals (7-12) it implies a significant amount of disturbances in the patients daily physical activities (Table 4).

IMPACT SCORE: A score of $29.11 \mathrm{SD} \pm 19.73$; is ten times more than the normal individuals indicates that there are wide range of disturbances in psycho-social function of the patients which they experience in their daily life (Table 4).

The relationship between the disease severity $\mathrm{FEV}_{1} \%$ predicted and HRQL was made obvious by staging the disease according to the GOLD and BTS guidelines. Once the COPD/Asthma has been diagnosed neither gender, smoking status nor socio-economic group predicted the level of HRQL. One of the most important implications of a non-linear relationship is that similar changes in disease severity may have a different effect on major HRQL.

The present results signify the clinical value of multidimensional and complex majors of HRQL previously described by others. ${ }^{18} \mathrm{~A}$ moderate association between HRQL and COPD/Asthma severity stage using $\mathrm{FEV}_{1} \%$ predicted was in another study also. However a large variation in deteriorations was observed with each stage of severity indicating that both clinical and HRQL measures should be considered in the assessment of these patients. On the other hand only a few 
studies have highlighted a relationship between disease severity and HRQL in COPD. A recent publication ${ }^{19}$ supports our findings by showing that GOLD stages of COPD severity differ significantly in HRQL. However it was observed that the upper limit of stage IV marks a threshold for dramatic worsening of HRQL, whereas a change from 0 -II does not correspond to any meaningful difference in HRQL. A moderate relationship between the disease stage and HRQL was found.

Our findings are very close to these results as patients with COPD/Asthma have significant decrease in HRQL and the latter deterioration in parallel with lung function impairment. As per one study it was observed that lung function and HRQL express several different aspects of disease severity in COPD/Asthma.

The correlation between $\mathrm{FEV}_{1} \%$ predicted and HRQL measurement vary between -0.902 and 1.0 , with the highest correlation (-0.902) between $\mathrm{FEV}_{1} \%$ predicted and SGRQ Total score (Table 8).

One reason for the difference in correlation between lung function and HRQL may be the influence of psychosocial variables on the HRQL outcome. The subjects in our study seemed to score their HRQL better, compared to other subject groups with similar lung function. An earlier study carried out supported the view that the association between lung function and HRQL can be predicted by perceived self-efficacy for functional activities. ${ }^{20}$ That study suggested that both biomedical and psychosocial influences should be taken into account in order to provide optimum assessment and treatment.

Using FVC \% predicted did not add any additional information; however, it supported the view that the level of lung function measured by volume has a similar but lower association with HRQL compared with FEV 1 $\%$ in subjects with COPD/Asthma (Table 8).

\section{CONCLUSION}

The study reveals that patients with COPD and asthma have an average HRQL with wide range of disturbances in physiological wellbeing and psycho-social functioning which they experienced in daily life. The level of HRQL in COPD and asthma subjects deteriorate considerably with increase in the severity of disease and such deterioration shows linear relation to the decrease in the $\mathrm{FEV}_{1} \%$ predicted normal values. Evaluating HRQL is useful in identifying patients at risk of steep decline for which preventive measures may be instituted.

\section{SCOPE OF THE STUDY}

Disease due to COPD and asthma are the largest public health problems of our society and there is currently no coordinated data collection for COPD and asthma in India. There is a need to develop a systematic approach to the surveillance of COPD and asthma to monitor disease levels, burden and trends to identify the potential for improved prevention and management of the disease.

\section{ABBREVIATION}

COPD: Chronic Obstructive Pulmonary Disease

HRQL: Health-related quality of life

SF-36: Short Form 36

SGRQ: St George's Respiratory Questionnaire

PCS: Physical Component Summary

MCS: Mental Component Summary

\section{CONFLICT OF INTEREST}

Authors declared there is no conflict of interest.

\section{ACKNOWLEDGEMENT}

We would like to express our gratitude to everyone who was instrumental in this study. We sincerely thank Dr. M. Rajshekar, Medical superintendent of $\mathrm{NMCH}$ and $\mathrm{RC}$, Raichur without whom this study would not have been possible.

\section{Author Profile}

- Dr. Ashok Kumar Malpani is a Professor \& Pharm D incharge at Navodaya Education Trust's Pharmacy college Raichur, Karnataka. He has 07 nos of journal paper; 05 nos of abstracts; more than 05 invited talks. He has organized 02 conferences as a convenor for the pharm D programme.

- Mr. Manjunath waggi is a lecturer at NET Pharmacy College Raichur, Karnataka. He has 02 nos of abstracts. 


\section{Highlights of Paper}

- HRQL in relation to SF-36: A PCS score of $40.46 \pm 7$ indicates below average health status, COPD and Asthma being significantly affecting the physical activity of the patients.

- A MCS had a score of $40.22 \pm 7.7$ denoting a significant decrease in the psychological wellbeing, social, role functioning of the COPD and Asthma subjects.

- HRQL in relation to SGRQ: A total score of 33.95 which are considered as an average quality of life when compared to normal subjects (The ideal total score desirable for a normal subject is 6.).

- HRQL in relation to COPD severity according to GOLD: The scores for SF-36 (PCS) were 43.72 in the stage I group and 32 in the stage IV group. The corresponding scores for SF-36 MCS were 42.11 and 33 in stages I and IV respectively. The level of SGRQ Total is follows: stage I: 22.90, stage II: 39.90 , stage III: 59.44 and stage IV: 67.84 respectively.

- HRQL in relation to COPD severity according to GOLD: The scores for SF-36 (PCS) were 43.72 in the stage I group and 32 in the stage IV group. The corresponding scores for SF-36 MCS were 42.11 and 33 in stages I and IV respectively. The level of SGRQ Total is follows: stage I: 22.90, stage II: 39.90 , stage III: 59.44 and stage IV: 67.84 respectively

- HRQL in relation to COPD severity according to BTS: The scores for SF-36 (PCS) were 43.72 in the stage 0 and 33.36 in stage III. The corresponding scores for SF-36 MCS were 42.11 and 35.10 in stages 0 and III, respectively. The severity grades of SGRQ Total scores as follows: stage 0: 22.90 , stage I: 37.24 , stage II: 53.19, and stage III: 64.18 . There was a statistically significant difference in the SGRQ Total scores between the severity groups.

\section{REFERENCES}

1. Buist AS, McBurnie MA, Vollmer WM, Gillespie S, Burney P, Mannino DM, et al. International variation in the prevalence of COPD (the BOLD Study): a population-based prevalence study. Lancet 2007; 370(9589): 741-50.

2. Gershon AS, Warner L, Cascagnette P, Victor JC, To T. Lifetime risk of developing chronic obstructive pulmonary disease: a longitudinal population study. Lancet 2011; 378(9795): 991-6.

3. Centers for Disease Control And Prevention (CDC). Chronic Obstructive Pulmonary Disease among Adults-United States, 2011. Mmwr Morb Mortal Weekly Rep. 2012; 61: 938. Available from: http://www.cdc.gov

4. Asthma. Available from:http://www.who.int/topics/asthma/en.

5. http://www.worldlifeexpectancy.com/cause-of-death/asthma/by-country

6. Ray D, Abel R, Selvaraj KG. A 5-yr prospective epidemiological study of chronic obstructive pulmonary disease in rural south India. Ind J Med Res. 1995; 101(0): 238-44.

7. Renwick DS, Connolly MJ. Prevalence and treatment of chronic airways obstruction in adults over the age of 45. Thorax 1996; 51(12): 164-8.

8. Mannino DM, Gagnon RC, Petty TL, Lydick E. Obstructive lung disease and low lung function in adults in the United States - Data from the National Health and Nutrition Examination Survey, 1988-1994. Arch Intern Med. 2000; 160(11):1683-9.

9. Sobradillo V, Miravitlles M, Jimenez CA, Gabriel R, Viejo JL, Masa JF, et al. Epidemiological study of chronic obstructive pulmonary disease in Spain (IBERPOC): prevalence of chronic respiratory symptoms and airflow limitation. Arch Bronconeumol 1999; 35(4): 159-66.

10. Jones PW. Quality of life measurement for patients with diseases of the airways. Thorax 1991; 46(1): 676-82.

11. Ware JEJ, Sherbourne CD. The MOS 36-item short-form health survey (SF-36) I. Conceptual framework and item selection. Med Care. 1992; 30(1): 473-83.
12. Jones PW, Quirk FH, Baveystock CM. The St George's Respiratory Questionnaire. Respiratory Medicine 199; 85(1): 25-31.

13. Pauwels RA, Buist AS, Calverley PMA, Jenkins CR, Hurd SS. Global strategy for the diagnosis, management, and prevention of chronic obstructive pulmonary disease: NHLBI and WHO Global Initiative for Chronic Obstructive Lung Disease (GOLD): executive summary. Respiratory Care 2001; 46(6): 798825.

14. BTS. BTS guidelines for the management of chronic obstructive pulmonary disease. The COPD Guidelines Group of the Standards of Care Committee of the BTS. Thorax 1997; 52(1): S1-28.

15. Jones PW, Quirk FH, Baveystock CM, Littlejohns P. A self-complete measure of health status for chronic airflow limitation. The St. George's Respiratory Questionnaire. American Review of Respiratory Disease 1992; 145(6): 1321-7.

16. Jones PW. Health status measurement in chronic obstructive pulmonary disease. Thorax 2001; 56(11): 880-7.

17. Jones PW. Interpreting thresholds for a clinically significant change in health status in asthma and COPD. European Respiratory Journal 2002; 19(3): 398404.

18. Wilson IB, Cleary PD. Linking Clinical Variables with Health related Quality Of Life. A Conceptual Model of Patient Outcomes. Jama 1995; 273(1): 59-65.

19. Incalzi AR, Imperiale C, Bellia V, Catalano F, Scichilone N, Pistelli R, et al. Do Gold Stages of COPD Severity Really Correspond To Differences In Health Status? European Respiratory Journal 2003; 22(3): 444-9.

20. Kohler CL, Fish L. The Relationship of Perceived Self efficacy To Quality Of Life in Chronic Obstructive Pulmonary Disease. Health Psychology 2002; 21(6): 610-4. 